\title{
UNA MIRADA A LOS ENTORNOS CONSTRUIDOS EN EL VALLE DE TAFÍ, TUCUMÁN (1 - 1000 AD)
}

\author{
Julián Salazar y Valeria L. Franco Salvi \\ CONICET - CEH "Prof. Carlos Segreti". Miguel C. del Corro 308 (5000). \\ jjsalba@hotmail;comvaleriafrancosalvi@gmail.com
}

Presentado el: 20/05/2009 - Aceptado 20/12/2009

\section{Resumen}

Este trabajo analiza los modos en que se constituyeron los paisajes del Valle de Tafí a través del primer milenio d.C. Los avances realizados hasta la actualidad, nos permiten plantear que fueron construidos en múltiples situaciones generadas por estrategias sociales y negociaciones permanentes entre agentes tanto humanos como no humanos a lo largo de varios siglos llevando a la coexistencia de prácticas "domésticas" y "comunales" en ámbitos indiferenciados, constituyéndose como la base de las posibilidades de reproducción de estas sociedades agrícolas.

Palabras claves: Paisaje - Unidades domésticas - Estructuras agrarias - Formativo

\begin{abstract}
This paper analyzes the ways in which Tafi Valley landscapes were constructed during the first Millennium. The advances actually developed, allow us to propose that they were constructed in multiple situations set up by permanent social strategies and negotiations between human and nohuman agents during several centuries, taking on to the coexistence of household and communal practices within undifferentiated settings, establishing the sources for the reproduction of possibilities for these agricultural societies.
\end{abstract}

Key words: Landscape - Households - Agricultural structures - Formative Period

\section{Introducción}

La arqueología en general, y la arqueología argentina en particular, como disciplina surgida dentro del esquema epistemológico moderno, desarrolló un marcado interés por los estudios del espacio, adoptando en algunas oportunidades la idea cartesiana del mismo como matriz bidimensional divisible, cuantificable y racionalizable por la mente humana. Dentro de esta perspectiva, el espacio -visto como exterioridad material, inmóvil y muertafue separado del tiempo, o en el mejor de los casos supeditado a él -como interioridad racional, dinámica y viviente- (Criado 1991, Piazzini 2006).

En repetidas ocasiones se prestó atención al espacio como un medioambiente geográfico y como un telón de fondo sobre el cual flotaba la cultura. Alternativamente, se le dio el papel de medio de adaptación el cual, en menor o mayor medida, determinaba el comportamiento del hombre. En este contexto, el relato arqueológico acerca de la domesticación en general le otorgó centralidad a los aspectos cronológicos (en el sentido de ubicación en una sucesión unilineal de hechos) de características culturales, o a las estrategias adaptativas de "sistemas" a medios. 
A nivel local, los estudios realizados en el Valle de Tafí también abordaron predominantemente las transformaciones producidas durante el primer milenio d.C. en términos de una creciente dominación del hombre sobre el medio, de la cultura sobre la naturaleza. Estas concepciones que han permanecido hasta momentos recientes sin cuestionamientos, están siendo reformuladas críticamente a nivel regional (Nielsen 1995, Haber 2001, 2006; Korstanje 2005; Quesada 2006; Delfino et al. 2007). Sólo recientemente se comenzó a reflexionar sobre las potencialidades que ofrece el estudio del espacio como aspecto central de la cultura. Ese cambio puede comprenderse en el marco de una transformación más abarcativa en las Ciencias Sociales que lleva a pensar ese aspecto como un componente esencial de la teoría sociocultural: los antropólogos están pensando y reconceptualizando su comprensión de la cultura en modos espacializados (Low y Lawrence 2003).

Si consideramos, junto a Ingold (1993) que el paisaje no es tierra (homogénea y cuantificable), no es naturaleza (como externa y contrapuesta a la cultura) y no es espacio (objetivo y vacío de significado), ¿Qué es entonces?

El paisaje, concebido como constructo social, dinámico y heterogéneo, se constituye como un ámbito esencial para el estudio de la producción y reproducción de la sociedad ya que en él se plasma la constante tensión y relación entre las estructuras sociales y las estrategias de los agentes. En la micro-escala podemos comenzar a explorar la intersección de procesos de largo plazo y agencias, las interacciones de la gente creando paisajes y los paisajes formando a la gente. Al mismo tiempo, el análisis de micro escala sólo puede tener sentido si las personas, sus cuerpos y biografías son ubicados en el contexto del paisaje. El reto es encontrar la manera de alcanzar esta integración sin priorizar a ninguno de los dos (Hodder 2000, Trifkovic 2006). El paisaje es tanto lo que la gente hace y percibe en la tierra como lo que había en la tierra antes de que eso ocurra (Potter 2004).

El estar-en-el-mundo de la gente, es decir la incorporación a lugares específicos o somatización de los contextos locacionales, es siempre histórico y espacialmente contingente. La idea estrecha y estática del espacio, debe ser ampliada para reconocer que, los paisajes están siempre en proceso, potencialmente conflictuados, desordenados y complicados. En este sentido, en una misma sociedad pueden encontrarse ámbitos espaciales, construidos e imaginados de distintas maneras en los cuales la gente se mueve, se comporta y se siente de formas diferentes según filiación, género, grupo social, étnico, etc. (Brumfiel 1992, Bender 2001, Hodder 2000, Hodder y Cessford 2004).

De esta manera, la visión predominantemente horizontal y sincrónica de los sitios arqueológicos, la cual se refuerza a través del predominio de estudios superficiales, dificulta el análisis de esas variables y estabiliza esas tensiones, conflictos y dinámicas. Por esto, consideramos como objetivo central, analizar los modos en que se constituyeron los paisajes del valle en el primer milenio d.C. mediante una visión integral que involucra en un mismo plano los aspectos espaciales, materiales y temporales de las prácticas.

Los avances realizados hasta la actualidad, nos permiten plantear que los paisajes aldeanos del valle de Tafí fueron construidos en múltiples situaciones generadas por estrategias sociales y negociaciones permanentes entre agentes tanto humanos como no humanos a lo largo de varios siglos, llevando a la coexistencia de prácticas "domésticas" y 
"comunales" en ámbitos indiferenciados, constituyéndose como la base de las posibilidades de reproducción de estas sociedades agrícolas.

\section{El espacio en la arqueología}

La variabilidad de maneras de entender el espacio que se han formulado en el último medio siglo hace necesaria una profunda revisión y crítica de las mismas. Sin embargo, las limitaciones editoriales sólo nos permiten tener en cuenta aquellas investigaciones que consideramos fundamentales por haber marcado tendencias predominantes, resultando esenciales para el desarrollo de los objetivos aquí propuestos.

Durante la década de 1960, se ubicó a la "cultura Tafí" -caracterizada por habitaciones de piedra de planta circular, cerámica tosca pintada de rojo y la utilización de menhires- entre las sociedades que más tempranamente manejaran la agricultura y la alfarería en el NOA (González y Núñez Regueiro 1960). El rol que tocaba jugar al espacio en esta explicación consistió en una leve modificación sufrida por los patrones culturales que traía un grupo humano desde su lugar de origen, quizás en el altiplano Boliviano (González 1963). La hipótesis que se proponía conservaba las propuestas de la arqueología tradicional (Willey y Philips 2001), la cual pretendía reconocer en el espacio la distribución de rasgos culturales a través de distintas vías de difusión. No importaba demasiado cómo se integraban las distintas materialidades en lugares específicos, o qué papel jugaba cada una en contextos culturales y espaciales diversos, sino si su forma era similar y su cronología podía ordenarse en secuencias lógicas de dispersión.

Distintas vertientes del pensamiento materialista, que comenzaron a introducirse en la arqueología nacional a partir de los 70 , introdujeron la idea de la cultura como medio del hombre para enfrentarse a la naturaleza, pensamiento surgido de las entrañas de la modernidad occidental (Ingold 2001, Piazzini 2006). Núñez Regueiro (1974) siguiendo esta línea de pensamiento, recalcó el dominio progresivo de la cultura sobre la naturaleza quedando expresado en posteriores trabajos específicos para el valle (Tartusi y Núñez Regueiro 1993) donde se consideró al espacio un indicador de las diferencias sociales, y de las relaciones de poder.

Paralelamente, desde la ecología cultural, Berberián y Nielsen (1988a) pusieron énfasis en los aspectos ecológicos del espacio los cuales imponían condicionantes -o determinantesal comportamiento humano. Los grupos sociales que habitaron el valle fueron interpretados en términos de sistemas socioculturales los cuales se relacionaban con el medio a través del sistema de asentamiento (Berberián y Nielsen 1988a). El estudio arqueológico de los mismos, que vinculaba tipos de biotopos a tipos de asentamientos, permitió afinar el conocimiento de las relaciones entre el espacio y sus ocupantes, pero casi exclusivamente en esos términos: en los del uso del primero por parte de los últimos. Sin embargo, dentro de este estudio de carácter más ecológico se introdujo un análisis de micro escala, en el cual sí se consideraban aspectos más subjetivos y culturales, relacionados al funcionamiento interno de las unidades domésticas (Berberián y Nielsen 1988b).

Bajo estas expectativas se propuso un modelo del desarrollo histórico de esos sistemas desde uno simple, con baja modificación del medio, caracterizado por la dispersión de los asentamientos de vivienda y una producción extensiva, hacia uno más complejo con mayor alteración del espacio, poblados concentrados y tecnologías de producción intensiva 


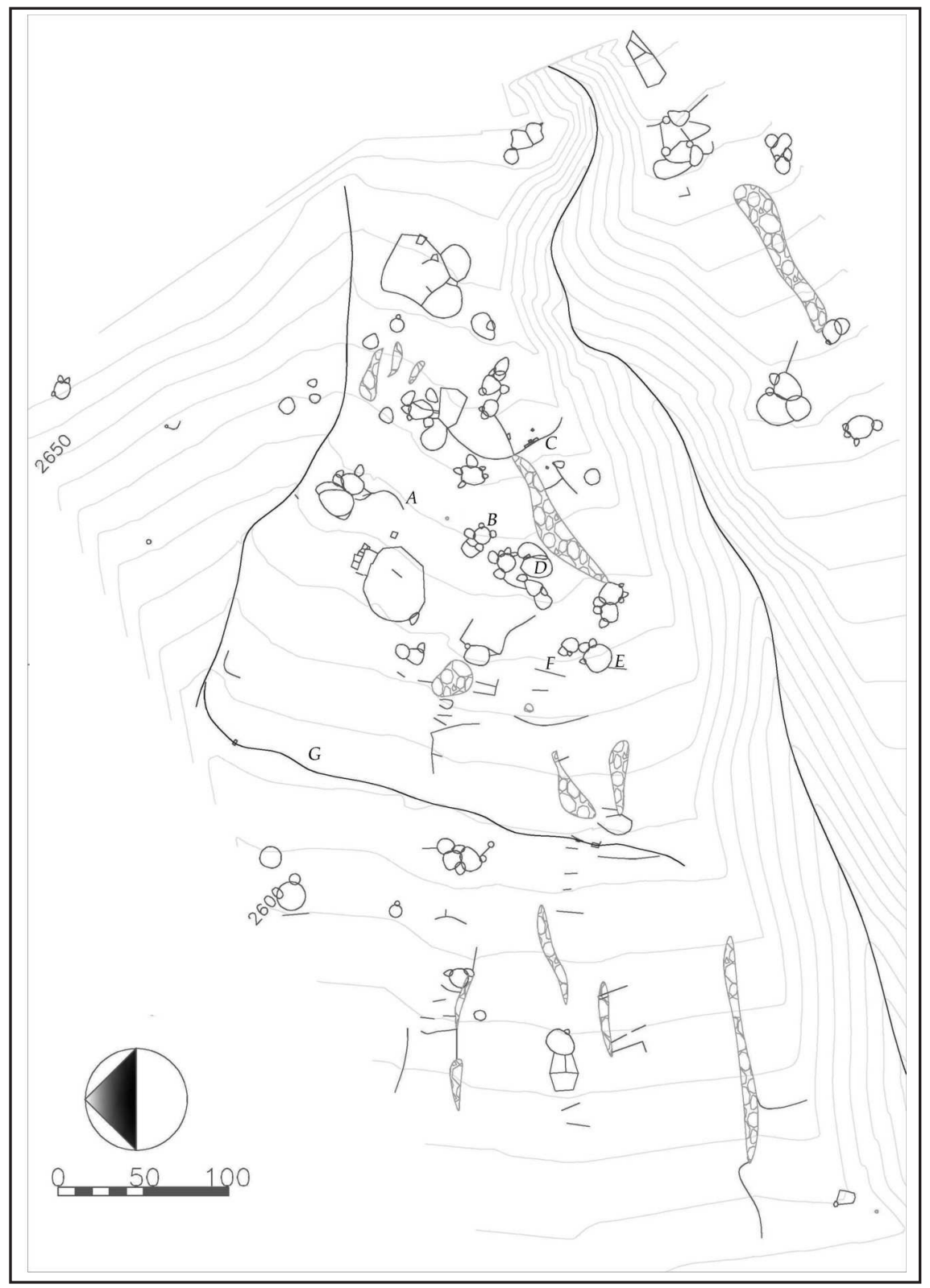

Figura 1. Sitio Arqueológico “La Bolsa 1". A) Línea de contención U14. B) Unidad 14. C) Andenes D) Cuadro de cultivo. E) Unidad 10. F) Línea de contención U10. G) EMA 1. 
(Berberián y Nielsen 1988a). Sin embargo, estas expectativas no pudieron ser corroboradas por los fechados radio-carbónicos que, aunque aún insuficientes, parecen ubicar a los sitios pretendidamente más tempranos, en los momentos más tardíos de la ocupación.

Recientemente, se desarrollaron en el valle interesantes aportes a la geoarqueología local, que han logrado obtener un detallado conocimiento de la relación entre estructuras arqueológicas y geoformas (Sampietro 2002), y de la organización de áreas de actividades dentro de las unidades habitacionales (Sampietro y Vattuone 2005). No obstante, el paisaje se ha seguido igualando a "medio geográfico" y se ha mantenido la aplicación del prototipo de homo oeconomicus para entender a los hombres que habitaron el lugar hace más de 1500 años. En este contexto, la relación de hombres y ambiente es entendida en términos físicos como una relación de uso y explotación, y la realidad que puede ser objeto de estudio arqueológico se reduce sólo a una fracción de la misma: el espacio externo y objetivo (Piazzini 2006).

Esto ha mantenido a las investigaciones en un carácter descriptivo sin profundizar en las variables subjetivas del entorno construido por el hombre, en su conceptualización, en el manejo de significados y del poder. Estas teorizaciones dejan de ver los orígenes sociales conflictivos de la espacialidad y su producción y reproducción problemática. En su lugar, la espacialidad es separada de su estructuración social y presentada como forma pura, como una serie opaca de hechos mapeables (Soja 1985).

\section{Entornos construidos en el Valle de Tafí}

Intentaremos introducirnos ahora en los modos en que fueron construidos paisajes y personas en el Valle de Tafí, en el transcurso del primer milenio d.C. poniendo un énfasis específico en el entorno construido de las viviendas y las estructuras agrícolas. En esta escala podremos ver cómo es que la espacialidad supera (aunque desde luego no descarta) aspectos funcionales y económicos, y se remite al modo en que la gente fue generando lugares específicos, que a la vez las constituyeron como personas, definiendo en esa relación los modos de estar-en-el-mundo (Richardson 2003). Esos modos serán contextualizados en las formas de habitar el espacio aldeano.

En la porción norte del valle, se pueden apreciar diversas estructuras que conformaron numerosos poblados de importantes dimensiones y notable visibilidad. En esta oportunidad nos interesa referirnos a un conglomerado aldeano instalado en un gran cono de deyección, denominado Sitio La Bolsa 1 (LB1).(Figura 1)

El asentamiento está conformado por numerosas unidades residenciales, que involucran entre 3 y 12 recintos cada una, y un complejo sistema de estructuras agrícolas entre las cuales se destacan aterrazamientos, montículos de despedre, líneas de contención, cuadros de cultivo y áreas de molienda extramuros. Los fechados obtenidos hasta ahora ubican su ocupación principal entre unos siglos antes de la era y el final del primer milenio d.C. Contemporáneamente, otros sitios en sectores aledaños (i.e. Carapunco, El Infiernillo, El Tolar, La Ciénaga, El Remate) presentan estructuras en superficie y contextos bastante similares (Berberián y Nielsen 1988a, Sampietro 2002, Cremonte 1996, Aschero y Ribotta 2007). 
Este conglomerado residencial se presenta como una unidad pero se constituye a partir de distintos eventos de construcción, mantenimiento, reorganización, abandono y reocupación, a través de varios siglos. Nuestros estudios han permitido a través de relevamientos y excavaciones en distintos sectores del mismo, comenzar a esbozar una historia del paisaje aldeano, la cual construimos a partir de dataciones absolutas y relativas

La ocupación inicial del sitio se remonta al menos a un siglo antes de la era. En la porción media del asentamiento se identificó una ondulación que lo atraviesa de manera transversal presentando una longitud de 321 metros y un ancho que oscila entre los 60 y 80 centímetros (Figura 1). Se realizaron tres excavaciones en distintos sectores del rasgo que permitieron reconocer la presencia de dos paleocauces arenosos superpuestos en la estratigrafía.

En la sección media de la estructura, se identificó superficialmente un muro de piedra que la atravesaba en sentido diagonal sureste-noreste. En ese sector, se decidió plantear una trinchera (T2) la cual permitió observar no sólo que la estructura de piedra presentaba bloques especialmente seleccionados por su forma y tamaño sino también que la misma se encontraba dividida al medio en el punto por donde habría circulado el agua. (Figura 2).

En la excavación realizada mediante estratos naturales se reconocieron nueve unidades estratigráficas. En este caso nos referiremos a la UE 215 la cual se interpreta como "basurero". Se trata de un depósito de $20 \mathrm{~cm}$ de ancho que presenta sedimento consolidado y una



Figura 2. Vista en Planta de la Trinchera 2, realizada en EMA1 
coloración denominada Dark Brown (Hue 10 YR 3/3) con un Ph fuertemente ácido (5). Se reconoció predominantemente cerámica ordinaria de pasta roja y antiplásticos gruesos $(91,2 \%)$, (y en menor medida cerámicas rojas y naranja con inclusiones finas $(7,2 \%)$. En el mismo nivel, se obtuvo un tiesto con forma de tubo de cerámica gris, sin inclusiones, de textura compacta y no decorada, y un fragmento de estatuilla antropomorfa en la que se representa ojos y boca en forma de "grano de café". Los fragmentos decorados fueron muy escasos (sólo el 0,63\%), todos ellos, presentando gruesas y profundas incisiones sobre bordes, asas y aplicaciones, lo que genera unos aserrados muy particulares (Figura 3). Las características de dichos motivos son bastante particulares y se diferencian notablemente de las que predominan en los conjuntos recuperados en contextos residenciales del sitio, fechados entre 200 y $800 \mathrm{AD}$.

Con respecto al material lítico, se identificaron numerosas lascas de cuarzo y andesita estando también asociado a ellas un artefacto de cuarzo con microretoque sumario de tamaño pequeño. Se reconocieron diferentes taxones (i.e un fragmento de pelvis, un incisivo y una epífisis suelta de húmero) correspondientes a Camelidae y otros completamente calcinados y, por lo tanto, difíciles de diferenciar que corresponderían a mamíferos grandes. En este conjunto faunístico se obtuvo una datación absoluta mediante C14 AMS de un navicular izquierda de Camelidae la cual fue datada en $2110 \pm 66 \mathrm{AP}$; calibrada con 68,2 por ciento de

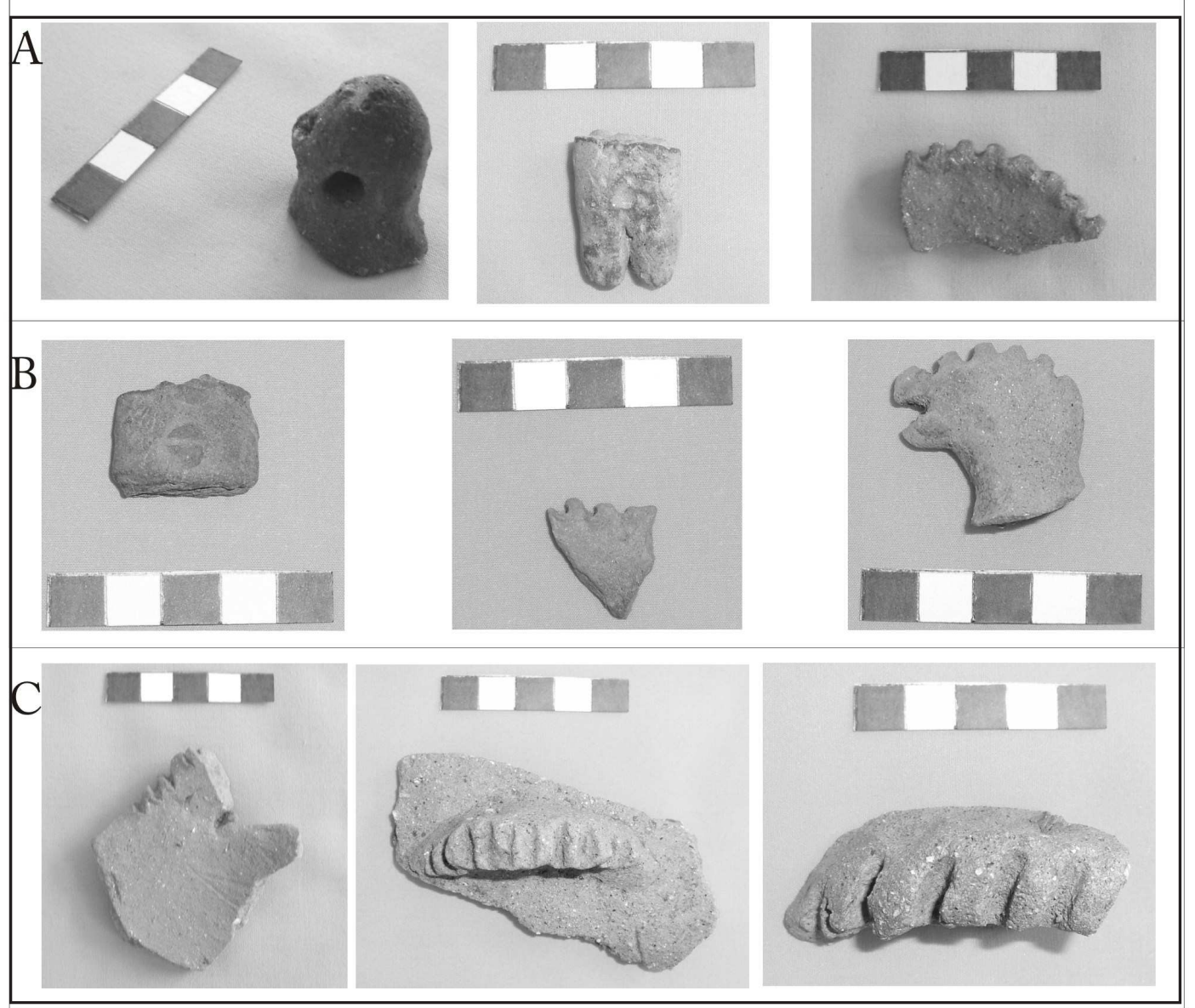

Figura 3. Fragmentos de cerámica procedentes de T2, EMA1.3A)UE212;3B) UE215;3C) UE216. 
confianza, entre 350a.C-320a.C y 210a.C-40a.C y con un 95,4\% de probabilidades entre el 360a.C. y 270a.C y entre el 260a.C y 30d.C.

Las evidencias de esta temprana ocupación resultan aún bastante aisladas pero aseguran de manera fidedigna la presencia de actividad antrópica en ese espacio en algún momento antes del inicio de la era, además de ofrecer un conjunto tecnológico con algunas diferencias respecto de los que aparecen en momentos más antiguos, siendo estas fundamentalmente la presencia de decoraciones con "aserrados" y la ausencia total de fragmentos cocidos en atmósferas reductoras.

En los inicios de la era se construyeron las primeras instalaciones residenciales. La Unidad 14 (LB1-U14), compuesta por nueve recintos, todos de morfología circular o subcircular, de diversas dimensiones, ocupa una superficie de $190 \mathrm{~m}^{2}$, la cual fue excavada en su totalidad. El patrón de construcción de esta vivienda no varía demasiado con respecto a otros sitios ocupados durante del primer milenio en el valle. Se constituye a partir de la integración de distintos espacios de planta circular, cerrados por altos y gruesos muros. Su vinculación también muestra un patrón recurrente, ya que las estructuras más pequeñas, de diámetros variables entre $2 \mathrm{~m}$ y $5 \mathrm{~m}$, se adosan y comunican exclusivamente a una estructura también circular de mayores dimensiones (10m de diámetro), interpretada en la literatura arqueológica como "patio".

El patrón organizativo de la unidad es radiocéntrico. El núcleo espacial es el patio (R1), al cual se adosan el resto de los recintos menores. El papel de centralidad de esta estructura es reafirmado por los análisis gamma (Hillier y Hanson 1984, Mañana et al. 2002), a través de los cuales se puede observar claramente cómo juega un rol jerárquico sobre el resto de estructuras en la unidad: controla el único acceso desde el exterior, y mantiene la exclusividad de las aberturas al resto de estructuras. Para llegar a cualquier recinto adosado se debe atravesar obligatoriamente ese lugar, restringiendo y dominando la circulación interna.

Frecuentemente el interior de los patios puede ser parcialmente percibido desde el exterior, mientras que el interior de los recintos adosados se mantiene privado a quienes no hayan atravesado el umbral principal. La visibilidad desde el interior también es limitada, teniendo en cuenta que los muros llegaban casi a los $2 \mathrm{~m}$ de altura y que los recintos menores seguramente estaban techados. Las viviendas se plantean entonces como un espacio distinto al afuera y diferenciado del resto de las viviendas.

Dentro del compuesto la circulación tenía como centro al patio. Pero éste no era un lugar vacío: en el centro del mismo se ubicó una estructura subsuperficial de piedra, de forma cilíndrica, tapada con una falsa bóveda, interpretada como cista. Ésta contenía dos entierros sucesivos, los cuales a su vez están constituidos por múltiples elementos. El entierro más antiguo, datado en $1799 \pm 37 \mathrm{AP}$, calibrado con el $68 \%$ de probabilidades entre 130 y $260 \mathrm{AD}$, está constituido por los restos óseos de un individuo en muy mal estado de conservación acompañados de un jarro (de pasta ordinaria de color rojo con un acabado de superficie muy irregular, que presenta un asa labio adherida en posición vertical, y en su borde opuesto una decoración aplicada al pastillaje con el motivo de una pequeña cara antropomorfa), una jarra (de pasta similar, con un acabado de superficie más uniforme, sin decoraciones y con una gruesa capa de hollín en su cara externa), numerosos fragmentos de vasijas con características similares y concentraciones de carbón que parece haber sido quemado in situ. 
Ninguna de las cerámicas presenta decoración compleja ni corresponde a lo que se conoce como pasta "fina" para el momento, siendo piezas que la literatura identifica como "ordinarias" o utilitarias. Sin embargo son las que acompañan al difunto que se entierra en el centro de la vivienda, y quizás las que lo acompañaron como parte de su vida, las que lo hicieron sujeto.

Por encima de él se depositó, en un momento posterior aún no establecido, otro cuerpo humano, el cual presenta peores condiciones de conservación que el anterior, acompañado de un puco de pasta gris sin decoraciones, fragmentos de cerámica ordinaria y nuevas evidencias de combustión. Sobre este entierro, cerrando quizás este evento inhumatorio, se exhumó una estatuilla antropomorfa de piedra, cuyo rostro muestra a una mujer llorando, la cual fue intencionalmente fracturada o "matada".(Figura 5)

Otros rasgos internos del patio fueron dos muros bajos ubicados frente a las entradas de R2 y R3 y una estructura semicircular adosada al muro noroeste de la estructura. Esta última no contenía materiales, salvo una pequeña estatuilla de cerámica que representaría posiblemente una mujer.

Alrededor de la cista, que contenía al ancestro y que referenciaba permanentemente su presencia, manteniendo su participación y mediación en la vida cotidiana, se daban diversas actividades, entre ellas el procesamiento de vegetales y el fraccionamiento de camélidos (Berberián y Nielsen 1988a, Sampietro y Vattuone 2005). Grandes y pesados morteros, con sus correspondientes manos se registraron en toda la superficie del patio. Algunos presentaban adherencias que fueron analizadas determinando la presencia de silicofitolitos de morfotipos asignables a zea mays.

Así mismo hay que considerar la práctica de continua depositación de estatuillas zoomorfas que representan camélidos (algunas de ellas presumiblemente llamas ya que muestran la marca de haber sido enlazadas)

Las vasijas de cerámica presentan predominantemente tamaños grandes y paredes gruesas. Los grupos tecnológicos dominantes corresponden a pastas gruesas y no uniformes cocidas en atmósfera oxidante, presumiblemente a bajas temperaturas.

En menor medida se presentan pastas finas de color beige, y grupos tecnológicos cocidos en atmósferas reductoras, constituyendo pastas grises y en menor medida negras, todas correspondientes a fragmentos de vasijas de tamaños pequeños. Las decoraciones se ejecutaron preferentemente sobre estos últimos grupos en los cuales se realizaron incisiones, constituyendo motivos geométricos, líneas curvas, campos rellenados por reticulados, etc. Varios motivos son muy similares a las decoraciones asignadas frecuentemente a estilos Candelaria, sobre todo la presencia de fragmentos de "mamelones" con decoraciones modeladas aplicadas al pastillaje. En solo tres casos se reconocieron motivos que pueden ser asignados a estilos aguada, en los cuales se representan, a un antropomorfo de frente portando un pectoral, una guarda de lanzas en posición vertical, y la repetición de dos dientes enfrentados entre si, que constituyeron un motivo similar a las "fauces" felínicas.

Restos de carbón vegetal obtenidos de la superficie ocupacional en un sector cercano a la puerta que vincula este espacio con el R6, no correspondientes a fogones sino productos de la limpieza de este último recinto, fueron fechados en $1236 \pm 37 \mathrm{AP}$. 


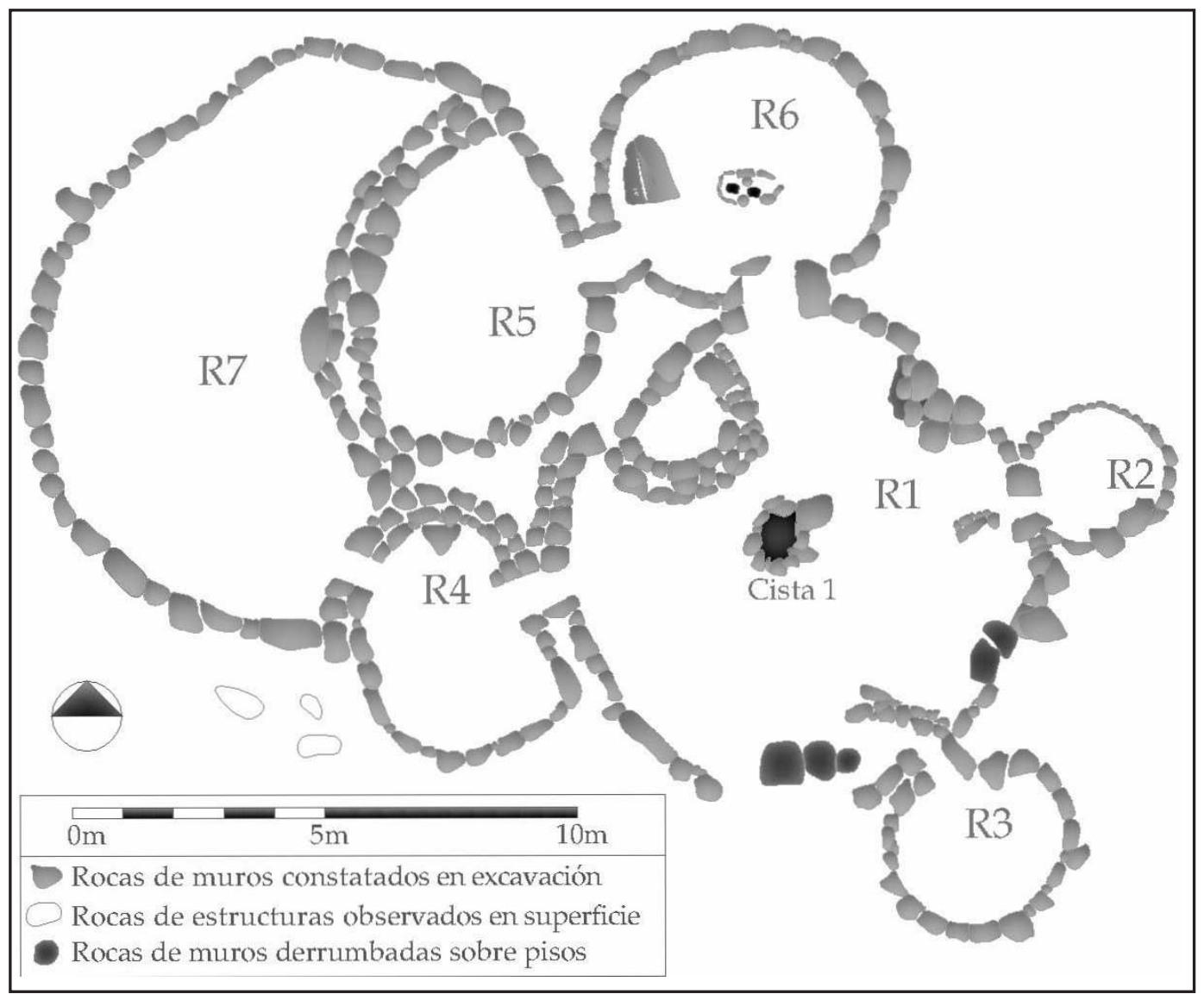

Figura 4. Planta de LB1-U14.

Dentro de los recintos adosados las actividades también eran ordenadas de manera radiocéntrica, frecuentemente en torno a una estructura central de combustión, como en el caso de R6 y de R4. Múltiples áreas de actividades alrededor de los mismos pueden inferirse a partir de los hallazgos realizados.

La cronología de los materiales hallados sobre los pisos habitacionales de recintos adosados cuenta con cuatro fechados radiocarbónicos, bastante contemporáneos entre sí. La muestra de material vegetal carbonizado extraída del piso de R2 arrojó una antigüedad de $1275 \pm 42$, calibrada con el $68 \%$ de probabilidades entre 680 y 775 d.C.; la recolectada en un rasgo de combustión sin estructura en el piso de R4, $1258 \pm 38 \mathrm{AP}$, calibrada con el $68 \%$ de probabilidades entre 680 y 780 d.C.; la obtenida en el piso de R6, $1330 \pm 30 \mathrm{AP}$, calibrada entre 650 y 770 d.C.

Esta cronología es consecuente con el resto de los fechados conocidos para conglomerados residenciales Tafí, los cuales se ubican en su mayoría en la segunda mitad del primer milenio (González y Núñez Regueiro 1960; Berberián y Nielsen 1988a; Cremonte 1996; Aschero y Ribotta 2007, Scattolín 2007, Scattolín et al. 2007) y es coetáneo con la ocupación final de la Unidad 10, la cual fue intensamente analizada en otra oportunidad (Salazar et al. 2008).

Estas características generales de las unidades se repiten una y otra vez en distintos contextos ambientales y relacionales del Valle. Las mismas aparecen de manera dispersa, 




Figura 5. Planta del piso habitacional de R1-U14.

como es el caso de LB2- U75A (Berberián y Nielsen 1988a), y concentradas, como en el sitio LB1. En los dos ámbitos los conjuntos residenciales se constituyen como entidades espaciales bien diferenciadas unas de otras.

En los sectores aldeanos más concentrados, los espacios entre los conjuntos están ocupados por diversas áreas de actividades: sectores de producción agrícola - montículos de despedre, canales, aterrazamientos y cuadros-, áreas de procesamiento de alimentos, espacios de molienda, etc. Las mismas no se distribuyen en las plantas de los sitios como el resultado de un trazado planificado o con crecimiento en torno a ejes o centros.

Asociados a la unidad 14 y 10 se registraron dos líneas de contención denominadas LC14 Y LC10 (Figura 1 A y F). Ambas poseen un largo que supera los 200 metros y un alto que oscila entre los 60 y $80 \mathrm{~cm}$. Se trata de bloques de piedra (rocas micácitas y graníticas locales) de importantes dimensiones alineados y con rocas más pequeñas de relleno que ocupan los 


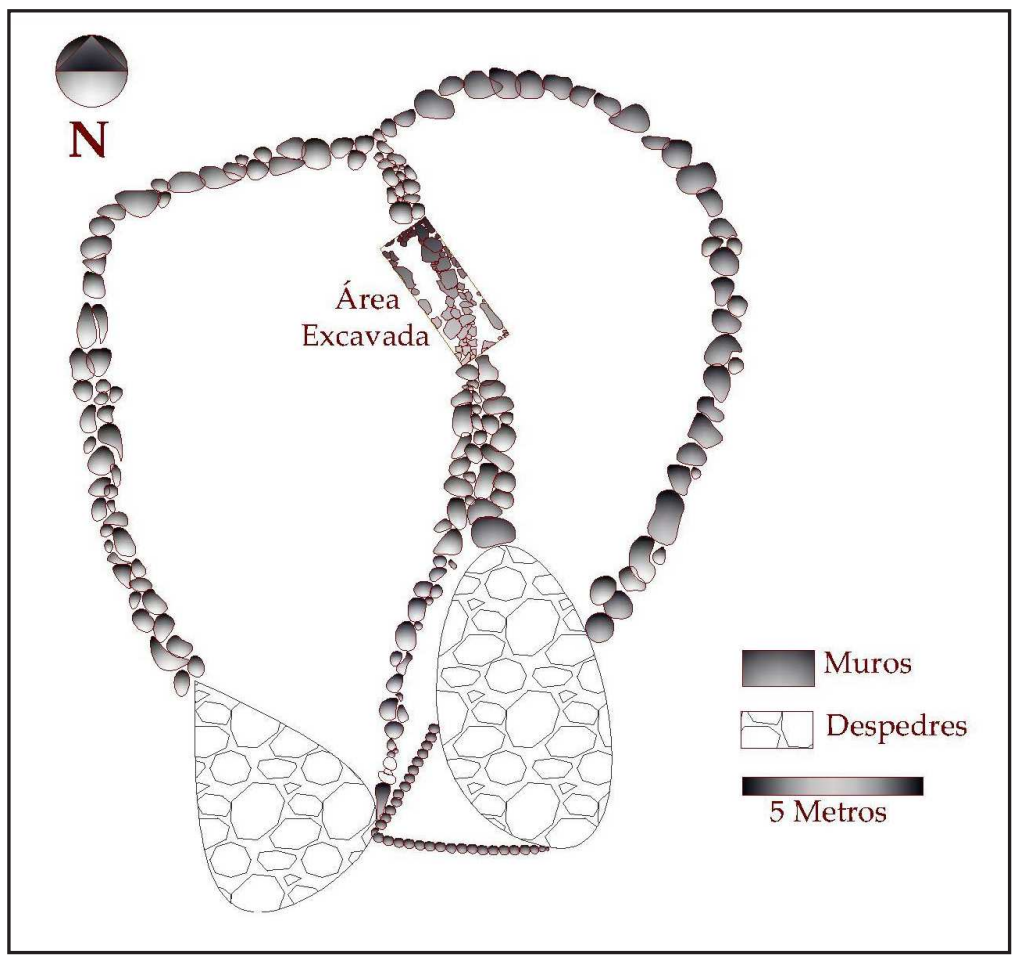

Figura 6. Planta Cuadro de Cultivo Sector Central LB1

intersticios entre un bloque y otro. Asimismo, dentro de este patrón de estructuras entremezcladas con el sector de residencias se pudieron registrar las características de un "cuadro de cultivo" de importantes dimensiones (20m x $12 \mathrm{~m}$ aproximadamente) (Figura 1B y 6) que habría sido construido con piedra seca sin utilizar argamasa o ligante de barro al igual que todas las registradas hasta el momento en las excavaciones de sectores extramuros. Las paredes habrían sido cuidadosamente confeccionadas para permitir el filtraje del agua en las temporadas lluviosas. Durante la excavación se obtuvieron escasos materiales arqueológicos en comparación con la densidad hallada en las unidades domésticas y los cuales en su totalidad se condicen con los encontrados para el primer milenio.De acuerdo a la evidencia arqueológica y estratigráfica estas construcciones serían posteriores a EMA 1 y contemporáneos a las viviendas.

\section{Algunas Consideraciones}

La aplicación en la arqueología argentina de modelos que reproducen la tensión entre naturaleza y cultura, propia de la modernidad, imposibilitó el estudio de una interesante dimensión de los procesos sociales del primer milenio en el noroeste, la cual no sólo implicó cambios sustanciales entre el hombre y el ambiente sino que también generó modificaciones profundas en las relaciones entre humanos, plantas, animales y espacios.

Volviendo a algunas de las líneas planteadas en este escrito se propone una mirada social al patrón espacial descrito. El sitio La Bolsa1 fue poblado por un progresivo proceso en el cual las estructuras (intra y extramuros), como partícipes materiales fundamentales de reproducción de la identidad, fueron usadas como marcas en el terreno; marcas que se constituían como legitimantes de una apropiación, pero también como jalones ordenadores 
de un espacio, a partir de los cuales se establecían los lugares en los que las personas se familiarizaban con su entorno, es decir los ámbitos donde se somatizaba un contexto social y cultural específico.

Estos primeros avances permiten pensar el paisaje del sitio la Bolsa como el resultado acumulado de años de construcción, uso, abandono y reutilización, es decir, de acumulación de trabajo campesino (Quesada 2005).

El primer momento de la ocupación, al menos unos siglos antes de la Era, no ha sido detectado aún más que en estructuras relacionadas a la agricultura cabiendo la posibilidad de que las prácticas relacionadas a la producción hayan sido fundamentales en la apropiación de nuevos espacios. Las estructuras agrícolas habrían significado un condicionante durante el ciclo de construcción de estructuras residenciales no solamente en el aspecto físico sino también social. Estratégicamente, se dejaron los terrenos menos abruptos para la producción y consecuentemente se instalaron en los sectores escabrosos.

En momentos posteriores al 200 d.C. el cono que albergaba al poblado ya estaría ocupado por viviendas y estructuras agrícolas que se entremezclaban en el paisaje, sin un orden claramente perceptible, pero sí con una lógica social: la de que las unidades domésticas se mantenían relativamente distantes y como bloques sensiblemente separados entre sí.

Dentro de los conjuntos habitacionales el patio central se constituía como espacio jerarquizado, el único visible y accesible desde fuera, el que dirigía todo el movimiento y comunicación de la vivienda; era el punto neurálgico alrededor del cual se ordenaba la vida dentro de la casa. En su seno, se ubicaban las perceptibles tumbas de los ancestros. Adosados a este lugar central, múltiples espacios privados a la vista desde afuera se establecían como el dominio de la unidad. La conformación de ese lugar, complicadamente construido y cargado de significado constituye un aspecto clave de la reproducción del habitus, a través del cual se habría reproducido la identidad de la unidad, fenómeno conceptualizado por Blanton (1994) como mensajes canónicos (la pertenencia a un nosotros), pero también se habría producido y legitimado la situación de poder de algunas personas del grupo sobre otras, en lo que Blanton llama mensajes indexales (la distinción entre nosotros).

Cada una de estas unidades se erigía separada de las demás pero en distintos tipos de relaciones de percepción. Con algunas se podían ver, con otras quizás oír. Los lazos de propincuidad habrían generado entornos espaciales distintos, en los cuales se habría tenido que resolver tensiones, en algunas ocasiones (como en el caso de LB1), mediante la cooperación $\mathrm{y}$, en otras, mediante el alejamiento. Si bien no contamos aún con datos cronológicos determinantes, los disponibles permiten al menos poner en duda la expectativa de que progresivamente se fueran implementando maneras de vivir y relacionarse al espacio más "eficientemente". Los resultados deben ser entendidos a partir diversas situaciones sociales resueltas con estrategias distintas dentro de un marco de estructuras limitantes mayormente compartidas.

Esto significó que las viviendas finalizaran ubicándose muy próximas unas y otras, lo que habría generado tensiones, acuerdos ó incluso activado determinadas estrategias. En base a nuestras observaciones podríamos plantear algunas posibles, como la construcción 
de pequeñas estructuras destinadas a la producción (v.g LC1-U10; LC1 U14; cuadro de cultivo), el distanciamiento de una unidad con otra y la enfatización de identidades domésticas a través de la materialidad de los ancestros. Muy lejos está esto de recurrir a la explicación de un creciente dominio del hombre sobre el medio, de la cultura sobre la naturaleza, como fruto de la maximización de la relación costos/beneficios.

A lo largo de este trabajo, se intentó graficar el modo en que un estudio del paisaje como fenómeno social puede ampliar las expectativas de la arqueología de acercarse a explicaciones de procesos históricos que superen la aplicación de principios apriorísticos aceptados acríticamente.

A partir de la aplicación de la arqueología del paisaje, bajo algunos presupuestos de la arqueología de la práctica, nos hemos acercado a los modos de construcción de lugares en el Valle de Tafí durante el primer milenio, los cuales se caracterizaron por una tensión constante entre la reproducción de la identidad de grupos domésticos autónomos, y el contradictorio intento de construcción de relaciones de poder hacia adentro de esas unidades. Lo que se había estructurado en el primer milenio, no era quizás un nuevo modo de adaptación al medio sino un modo distinto de entender las relaciones entre los hombres: más que paisajes domésticos, lo que había aparecido eran hombres domésticos. El paisaje fue construido y entendido en esa lógica, que es una interesante dimensión en la que se podrían analizar en profundidad otros fenómenos involucrados en el proceso: construcción de lugares públicos, estructuración del entorno valluno, relaciones con lugares más allá del valle y relación con recursos salvajes.

\section{Agradecimientos}

Queremos agradecer especialmente a nuestro Director, Dr. Eduardo Berberián, el apoyo y guía constante que ha dado a este proyecto. A todos los miembros de nuestro equipo, que han colaborado en las distintas etapas de esta investigación, en especial quienes han participado en los trabajos de campo (Guillermo, Julio, Diego, Julián). A Benito Cruz y familia, y a Miguel Romero. Al laboratorio de AMS de Arizona, por la realización de algunos de los fechados que aquí se presentan de manera gratuita. Estos trabajos fueron financiados parcialmente con los fondos de dos subsidios otorgados por el CONICET y el MINCyT-Pcia. de Córdoba-

\section{Bibliografía citada}

Albeck, M.

2000 La vida agraria en los Andes del Sur. Nueva Historia Argentina: los pueblos originarios y la conquista. Ed. por M. Tarragó pp: 187-228. Sudamericana Bs. As.

Aschero C. y E. Ribotta

2007 Usos del espacio, tiempo y funebria en El Remate (Los Zazos, Amaicha del Valle, Tucumán). En Paisajes y procesos sociales en Tafí del Valle. Compilado por Arenas, P, B. Manasse y E. Noli: 79-94. Tucumán.

Bender, B.

2001 Introduction a Contested Landscapes: movement, exile and place. Ed. Por B. Bender y M. Winer: 1-18. Berg Publishers. 
Berberián, E. E. y A. E. Nielsen

1988a Sistemas de asentamiento prehispánico en la etapa Formativa del valle de Tafí (Pcia. De Tucumán- Rep. Arg.) en Sistemas de Asentamiento Prehispánicos en el Valle de Tafí. Editado por E. Berberián: 21-51. Editorial Comechingonia. Córdoba.

1988b Análisis funcional de una unidad doméstica de la etapa Formativa del valle de Tafí (Pcia. De Tucumán- Rep. Arg) en Sistemas de Asentamiento Prehispánicos en el Valle de Tafí. Editado por E. Berberián: 53-67. Editorial Comechingonia. Córdoba.

Blanton, R. E.

1994 Houses and Households: a comparative study. Plenum Press. New York.

Brumfiel, E.

1992 Distinguished lecture in Archaeology: Breaking down and entering the ecosystemgender, class and faction steal the show. American Anthropologist Vol 94, No3: 551-567.

Cremonte, B.

1996 Investigaciones arqueológicas en la Quebrada de la Cienaga (dto. Tafí, Tucumán) Tesis para acceder al grado académico de Doctora en Ciencias Naturales. UNLP.

Criado Boado, F.

1991 Construcción social del espacio y reconstrucción arqueológica del paisaje. Boletín de Antropología Americana 24: 5-29. México.

1999 Del terreno al espacio: planteamientos y perspectivas para la arqueología del Paisaje. CAPA 6. Grupo de Investigaciones en Arqueología del Paisaje. Santiago de Compostela.

Delfino, D; V Espiro; R Díaz.

2009 Modos de vida situados: el formativo en Laguna Blanca. Andes XX; Antropología e Historia. Salta: centro promocional de investigaciones en Historia y Antropología "Dr. Guillermo Madrazo" Ed. CEPHIA.

Dobres, M. y J. Robb

2000 Agency in Archaeology. Paradigm or Platitud?. En Agency in Archaeology. Ed. por Dobres, M. y J. Robb: 3-17.

2005 Doing agency: introductory remarks on methodology. Journal of archaeological method and theory. Vol XII. N ${ }^{\circ}$ 3: 159-166.

González, A. R.

1963 Las tradiciones alfareras del Período Temprano del N.O. Argentino y sus relaciones con las de las Areas Aledañas. Anales de la Universidad del Norte. N 2: 49-65. Antofagasta.

González, A. R. y V. Núñez Regueiro

1960 Prelimanary Report on Archaeological Research in Tafí del Valle, NW Argentina. Akten del 34 amerikanisten Kongress : 18-25. Viena

Gramsch, A.

1996 Landscape Archaeology: of Making and Seeing. Journal of European Archaeology. 4: 1938. 
Haber, A.

2001 La domesticación del Oasis. Actas del XIII Congreso Nacional de Arqueología Argentina. Tomo I: 451-466.Córdoba.

2006 Una arqueología de los Oasis Puneños. Domesticidad, Interacción e Identidad en Antofalla. Primer y Segundo Milenios d.C. Jorge Sarmiento Editor- Universitas Libros. Córdoba.

Hodder, I.

2000 Agency and individualism in long term processes. Agency in Archaeology. Paradigm or Platitud?. En Agency in Archaeology. Ed. por

2004 The "Social" in Archaeological Theory: An Historical and Contemporary Perspective en Companion to Social Archaeology. Meskell y Preucel (eds): 23-42 Blackwell. Oxford

Hodder, I y C. Cessford

2004 Daily practice and social memory al Catalhöyük. American Antiquity. Vol 69. №1: 1740.

Ingold, $\mathrm{T}$.

1993 The temporality of Landscape. World Archaeology Vol 25 N²: 152-174.

2001 El forrajeo óptimo y el hombre económico. En Naturaleza y Sociedad. Perspectiva antropológica. Ed. Por P. Descola y G. Palsson: 37-59. Siglo XXI, México.

Korstanje, A

2005 La organización del trabajo en torno a la producción de alimentos en Sociedades Agropastoriles Formativas (Provincia de Catamarca, República Argentina). Tesis Doctoral en Arqueología. Facultad de Ciencias Naturales e IML UNT, Tucumán.

Low, S. M. y D. Lawrence Zuñiga

2003 Locating Culture. En The Anthropology of Space and Place. Locating Culture. Editado por Low, S. M. y D. Lawrence Zúñiga. 1-47. Blackwell Publishing.

Lumbreras, L.

1969 De los pueblos y las culturas y las artes del antiguo Perú. Monchoa Campodónico Editores Asociados. Lima

Mañana, P., R. Blanco y X. Ayán

2002 Arqueotectura 1: Bases teórico metodológicas para una arqueología de la Arquitectura. TAPA 25.

Marcus, J and Ch. Stanish

2006 Agricultural Strategies. Costen Institute of Archaeology. University of California, Los Angeles.

Nielsen, A.

1995 Architectural performance and the reproduction of social power. En Expanding Archaeology Ed por: J. Skibo, W. Walter y A. Nielsen: 47-66. U of UTA Press. Salta Lake City.

Núñez Regueiro, $V$.

1974 Conceptos instrumentales y marco Teórico en relación al análisis del desarrollo Cultural del Noroeste Argentino. Revista del Instituto de Antropología. № 5: 169-190. Córdoba. 
Olivera, D.

1991 Tecnología y Estrategias de adaptación en el Formativo (Agroalfarero Temprano) de la Puna Meridional Argentina. Un caso de Estudio: Antofagasta de la Sierra (Catamarca, RA). Tesis Doctoral Inédita. U.N. La Plata.

Parker Pearson, M. y C. Richards

1994 Ordering the world: perceptions of architecture, space and time. En Architecture and order: approaches to social space. Ed por Parker Pearson and Richards. 1-37 Routledge.

Pauketat, Timothy R.

2001 Practice and history in archaeology. An emerging paradigm. Anthropological Theory Vol 1(1): 73-98

Piazzini, C.

2006 Arqueología, espacio y tiempo: una mirada desde Latinoamérica. Arqueología Suramericana Vol II, N¹: 3-25.

Potter, J.M.

2004 The Creation of Person, the creation of place. Hunting landscapes in the American Sothwest. American Antiquity. Vol 69 NN$^{\circ}$ 2: 322-338.

Quesada, M

2005 Paisajes agrarios del área de Antofalla. Procesos de trabajo y escalas sociales de la producción agrícola (Primer y segundo milenios d.C.)Tesis doctoral en Ciencias Naturales. Facultad de Ciencias Naturales y Museo Universidad Nacional de La Plata. Buenos Aires.

2006 El diseño de las redes de riego y las esclas sociales de la producción agrícola en el $1^{\circ}$ Milenio DC (Tebenquiche Chico, Puna de Atacama). Estudios Atacameños No 13, pp 31-46.

Richardson, $\mathrm{M}$.

2003 Being in the Market vs. being in the Plaza: material culture and the construction of social reality in Spanish America. En The anthropology of Space and Place. Locating Culture Ed. Por Lawrence y Zuñiga: 74-91.

Sampietro, M.M.

2002 Geoambientes y sitios arqueológicos formativos en el valle de Tafí (Noroeste-República Argentina). Cuadernos del Instituto de Antropología y Pensamiento Latinoamericano 19: 599-611. Buenos Aires.

Sampietro, M. y M. Vattuone

2005 Reconstruction of Activity Areas at a Formative Household in Northwest Argentina. Geoarchaeology: an Internacional Journal. Vol XX. No 4: 337-354.

Scattolín, C.

2007 Santa María antes del año mil. Fechas y materiales para una historia cultural. En Sociedades Precolombinas Surandinas: Temporalidad, Interacción y Dinámica cultural del NOA en el ámbito de los Andes Meridionales.Buenos Aires: Instituto de Ciencias Antropológicasp. 203219. 
Scattolín, C., L. Domingorena, L. Cortés, F. Bugliani, M. Calo, A. Izeta y M. Lazzari

2007 Cardonal: Una aldea formativa entre los territorios de Valles y Puna. En Cuadernos de la Fucultad de Humanidades y Ciencias Sociales. 32: 211-225. UNJu. Jujuy.

Soja, E

1985 La espacialidad de la vida social: hacia una reteorización transformativa. Social relations and spatial structures. Londres. Traducción: H.A Torres.

Tartusi, M. y V. Núñez Regueiro

1993 Los centros ceremoniales del NOA. Publicaciones 5. Serie: Ensayos 1. Instituto de Arqueología. Tucumán.

Trifkovic, V.

2006 Persons and Landscapes: shifting scales of landscape archaeology. En Confronting scale in archaeology. Issues of theory and practice. Ed. Por G. Lock y B. Molineaux: 257-273. Springer

Willey, G.R. y P. Phillips

2001 [1958] Method and Theory in American Archaeology. University of Alabama Press. Alabama. 